\title{
ESTRATÉGIAS TECNOLÓGICAS NA PRÁTICA PEDAGÓGICA
}

\author{
Vania Seegger'; Suzy Elisabeth Canes²; Carlos Alberto Xavier Garcia ${ }^{3}$ \\ 1 Pós-Graduada em Educação: Interdisciplinaridade e Transversalidade pela Universidade Federal do \\ Pampa, Campus São Gabriel. \\ vaniaseeger@gmail.com.br \\ ${ }^{2}$ Professora Assistente da Universidade Federal do Pampa - Campus São Gabriel \\ suzycanes@unipampa.edu.br \\ ${ }^{3}$ Técnico em Assuntos Educacionais da Universidade Federal do Pampa - Campus São Gabriel \\ cxaviergarcia368@gmail.com
}

\section{RESUMO}

A sociedade contemporânea caracteriza-se por um avanço tecnológico muito rápido e diversificado, fazendo com que ocorram mudanças na vida das pessoas e, refletindo nas relações de âmbito político, a incorporação de novas tecnologias só terá sentido se contribuir para a melhoria da qualidade do ensino, e tê-la por si só não é garantia de qualidade na educação. 0 processo ensino e aprendizagem revelam-se na práxis do professor e de como este e alunos utilizam os recursos tecnológicos disponíveis. A presença da tecnologia deve servir para o enriquecimento do ambiente educacional, propiciando a construção do conhecimento por meio de uma atuação ativa e crítica por parte de alunos e professores. $O$ presente trabalho tem como propósito levar à reflexão sobre a prática educativa, focando para Estratégias Tecnológicas na Prática Pedagógica e as ferramentas digitais utilizadas em sala de aula, enfatizando as tecnologias digitais no processo ensino aprendizagem, apresentando uma análise sobre a utilização do computador na educação e identificando esta ferramenta como sendo de grande valia na construção do conhecimento.

Palavras-chave: Ferramentas Digitais, Educação, Práticas Pedagógicas.

\section{ABSTRACT}

Contemporary society is characterized by a very fast technological advancement and diversified, making occurring changes in people's lives and reflecting on the political relations, the incorporation of new technologies will only have sense to contribute to improving the quality of education, and have it by itself is no guarantee of quality in education. The teaching and learning is process are in the practice teacher and as a teacher and students use the technological resources available. The presence of technology should serve to enrich the educational environment, promoting the construction of knowledge through an active and critical on the part of students and teachers. The present work aims to lead to reflection on educational practice, focusing on Technological Pedagogical Strategies in Practice and the digital tools used in the classroom, emphasizing digital technologies in the learning process, presenting an analysis on the use of computers in education and identifying this tool as being of great value in the construction of knowledge.

Keywords: Digital Tools, Education, Pedagogical Practices. 


\section{INTRODUÇÃO}

Com a utilização de tecnologias digitais no ensino/aprendizagem surgiram novas possibilidades, democratizando o acesso aos diferentes níveis e modalidades de ensino. Com as novas tecnologias, como internet e ambientes virtuais de aprendizagem, ampliou-se o diálogo entre todos os envolvidos no processo, dentro deste novo paradigma. Alunos e professores estão frente a um novo modo de ensinar e aprender, rompendo barreiras com a criação de novos espaços de aprendizagem.

Quando o professor convida o aluno a um estudo virtual de informações, ele não apenas lança mão da nova mídia para potencializar a aprendizagem de um conteúdo curricular, mas acima de tudo contribui pedagogicamente para a inclusão deste educando na tecnologia digital.

Contudo, a contribuição pedagógica para a inclusão na tecnologia exige um aprendizado prévio por parte do professor, uma vez que não basta convidar a um site para se promover inclusão digital; ele precisará operacionalizar os recursos tecnológicos e desenvolver novas formas de ensinar e de aprender. Essa questão, no entanto, diz respeito à formação do professor - aquela que poderá ser desenvolvida na sua própria Escola e de forma continuada, pois hoje com a tecnologia basta ter o apoio institucional que prioriza a qualidade do trabalho educacional.

\section{O AVANÇO DA EDUCAÇÃO COM O USO DE NOVAS FERRAMENTAS PEDAGÓGICAS}

O profissional da educação, na ânsia por inovação nas Práticas Educativas, vem repensando suas formas de ensinar e aprender, julgando maneiras de formatar novas ideias, na busca de suportes para ampará-las, testando equipamentos e materiais, reorganizando espaços, ora em conflito, ora em harmonia na busca de superar dificuldades de inovação, onde muito ainda se abstém da utilização de apenas um quadro verde ou branco no medo de se permitir a inovação.

Em alguns momentos no passado as aulas foram desenvolvidas com algumas ferramentas enquadradas na metodologia do ensino e aprendizagem da época, e a pergunta constante: "Como despertar maior interesse de quem vem em busca de saber, diante do crescente avanço tecnológico e que ainda se percebe a mesmice no dia a dia do professor?".

A agilidade com que todas as áreas do conhecimento vêm se desenvolvendo, torna urgente a reflexão e tomada de decisões sobre o espaço pedagógico e a utilização das novas tecnologias.

Justo (2001, p. 72) comenta:

[...] não são só os computadores que mudam rapidamente, mas também os processamentos e metabolismos do ser humano. Não se trata de visualizar o perfil da sociedade contemporânea apenas na política, economia, nas artes e tecnologia, mas correlativamente, apreender a fisionomia do sujeito embrenhado nela. Como o ser humano está respondendo ou se adaptando ativamente às exigências da sociedade? Como está direcionando e remodelando sua sociabilidade no cotidiano, sua vida efetiva, seus hábitos e afazeres, enfim, que subjetivações estão emergindo?

O atual contexto questiona as relações e as formas de organização e produção de conhecimentos escolares, e se sabe que a escola permaneceu a margem das transformações ocorridas durante o século XX. A Escola deve modernizar-se, oferecendo aos alunos uma metodologia que esteja de acordo com a atualidade; não se pode mais dispor como único recurso o quadro de giz, pois este já está ultrapassado. Tem-se que inovar, investindo em tecnologia digital 
nas salas de aula, garantindo assim um ensino de qualidade, onde o que se quer é uma Escola Inovadora que o aluno esteja inserido na inclusão digital.

Atualmente, com o crescente desenvolvimento da tecnologia, surgem ambientes digitais modernizados com as novas tecnologias digitais; estes são ambientes de aprendizagem e desenvolvimento educacionais interativos, onde o educador assume o papel de mediador das aprendizagens. De outro lado, o educador deverá assumir-se com critérios metodológicos fazendo análise cuidadosa dos materiais que coloca a disposição das crianças. Sabe-se que alguns programas trazem retrocesso em termos de conhecimento pedagógico, em algumas vezes bloqueando que a criança encontre respostas variadas, e também espaço para a criação.

Esta discussão volta-se para questões acerca da incorporação das tecnologias digitais às ações educativas formais, e o papel do professor frente às atuais demandas trazidas por essas tecnologias digitais que traz possibilidades interativas para a educação, as quais, em muitas Escolas ainda não foram incorporadas nas práticas docentes, independentemente da adoção, ou não, dessa nova linguagem.

Tais possibilidades interativas podem trazer para a docência novos encaminhamentos quanto ao processo de aquisição do conhecimento pelo aluno. Entende-se que a utilização das tecnologias digitais deva ser assumida como parte da cultura escolar. Embora seja inegável a importância que se atribuí a essas novas tecnologias no âmbito da escola.

Como indica Arruda (2004), existe um descompasso entre o domínio que o docente apresenta destas novas linguagens frente aos conhecimentos que seus alunos possuem. Este ponto registra-se como um complicador a mais para o docente que, além de necessitar possuir um conhecimento específico acerca das possibilidades postas pela disciplina escolar a qual leciona, deverá também ser capaz de identificar as tecnologias digitais como linguagem favorecedora para apreensão da realidade.

Como o docente fará este último movimento sem apresentar, até mesmo, conhecimentos básicos na área da informática?

Destaca-se que conhecimentos básicos mostram-se muitas vezes insuficientes pelo professor, para a compreensão das potencialidades das tecnologias digitais para o ensino, deve-se promover a discussão sobre a incorporação das novas ferramentas tecnológicas como processo de ensino-aprendizagem, na busca por inovação e como meio de interação aluno/professor. Cabe à escola proporcionar espaço de formação em tecnologia digital ao corpo docente, para que este se sinta seguro e capaz de desenvolver atividades interativas de sua práxis junto aos discentes os quais estão sob sua responsabilidade.

Esta discussão volta-se para questões acerca da incorporação das tecnologias digitais às ações educativas formais, e o papel do professor frente às atuais demandas trazidas por essas tecnologias. O objetivo é determinar em que medida as práticas pedagógicas desenvolvidas na sala de aula estão orientadas para a qualidade do processo ensino-aprendizagem com auxilio dessas novas tecnologias.

A todas as atividades corriqueiras do dia a dia da educação, está uma imensa diversidade de meios de comunicação que cobre países interligando continentes e chegam às empresas, casas e escolas através de canais de micro-ondas, fios telefônicos, cabos, enfim, informações que invadem ambientes e que, muitas vezes, são transformadas em conhecimento no âmbito escolar.

Analisando o crescimento das tecnologias digitais e dos serviços oferecidos à sociedade atual, é crescente a necessidade da inclusão digital dos cidadãos nesse modo de vida. Ao acontecer o uso destes recursos tecnológicos, eles devem ser apropriados de meios onde à tecnologia da informação e comunicação (TIC) direcione-se para fazer valer a inclusão dos 
indivíduos neste ciberespaço. Deste modo, a escola deve apresentar-se como ambiente capaz de fazer imergir tais tecnologias a serviço de uma metodologia de ensino a favor da interação dos alunos nesta sociedade da informação anulando, assim, as diferenças sociais não pertinentes a este processo.

Com a utilização das tecnologias que colaboram para a apropriação de um ambiente de comunicação, o computador e seus inúmeros recursos destacam-se como ferramenta de acesso. $O$ tema inclusão digital no ambiente escolar como uma ação educacional que envolve o professor, ao capacitar-se para apropriação e ouso ideal de recursos tecnológicos, e o aluno como sujeito no espaço de interação e comunicação de novas formas de aprender e ensinar.

Desta forma o objetivo deve ser definido como o de analisar a escola como espaço de interação e comunicação onde o aluno apropria-se das tecnologias, como caminho a ser traçado.

De nada adianta a escola disponibilizar tais tecnologias se estas não forem apropriadas e entendidas pelos professores os quais fazem um papel fundamental neste processo, é através da interação por parte dos professores com os recursos tecnológicos que eles acabam por interagir com a realidade na qual o aluno está inserido.

As novas tecnologias oferecem novas possibilidades de aprender e devem tornar-se o centro de uma nova forma de aprendizagem.

A partir de 1980, os computadores de uso pessoal juntamente com o desenvolvimento de jogos e sites educacionais, fazem surgir o computador como uma extensão das capacidades cognitivas humanas que ativam o pensar, o criar e o memorizar.

Segundo Pretto e Costa Pinto, essas máquinas não estão mais apenas a serviço do homem, mas interagindo com ele, formando um conjunto pleno de significado. A partir de 1995, a Internet se expandiu com um grandioso poder de expressão a nível individual e coletivo ampliando em larga escala o número de usuários. Diante desse contexto, percebe-se que os professores estão sendo intimados para entrar neste novo processo de ensino e aprendizagem, nesta nova cultura educacional, as tecnologias são a base para o compartilhamento de ideias e disponibilizam levar a mesma informação a um grande grupo. A utilização pedagógica da Internet é um desafio que os professores e as escolas estarão enfrentando neste século, que pode apresentar uma concepção socializadora da informação.

A Internet vem, cada vez mais, atingindo o sistema educacional e as escolas. As redes são utilizadas no processo pedagógico e como ferramenta no processo ensino-aprendizagem, para romper as paredes da escola, bem como para que aluno e professor possam conhecer o mundo e as novas realidades, as diferentes culturas, desenvolvendo a aprendizagem através da participação colaborativa e interativa.

\section{METODOLOGIA}

A metodologia adotada é a pesquisa qualitativa baseada em bibliografias impressas e digitais que tratam do assunto e contribuem para uma mudança de postura frente a um tema recorrente e atualmente muito discutido e envolvente que está alterando culturas, crenças, procedimento no trabalho, o comércio e toda estrutura social.

No momento de delinear a forma como as investigações seriam realizadas, considerou-se: direcionar a pesquisa à área educacional, onde se pretendia obter dados descritivos sobre processos que possibilitassem a compreensão do tema em estudo, sob a visão do próprio pesquisado; sendo a pesquisadora comprometida com a educação, pretende-se utilizar este estudo para reunir reflexões que ampliam e aprofundam práticas e estudos sobre o uso das 
tecnologias digitais como ferramenta pedagógica no ensino aprendizagem, e o uso das mesmas como campo do saber e nova forma de atuar e de pensar potencializando conhecimentos e colher subsídios para refletir sobre o uso das tecnologias digitais e as práticas pessoais.

Uma vez que a pesquisa requer regras precisas, utilizou-se entrevista escrita para a coleta de dados pretendidos, que permitiram melhor compreensão do comportamento dos envolvidos no processo e a apreensão de detalhes por questionário escrito para a coleta de dados pretendidos. Para tanto, foram selecionados seis educadores de Ensino Fundamental, sendo duas professoras de Escola Estadual e quatro professores de Escola Municipal, todas de escolas de São Gabriel- RS, e que foram selecionados como sujeitos desta investigação. Com relação ao tempo de serviço destes professores entrevistados, os mesmos possuem entre dezenove e vinte e seis anos de atuação no magistério. Neste trabalho não serão mencionados os seus nomes e sim através de letras de $\mathrm{A}$ a $\mathrm{F}$. Os tópicos que seguem referem-se às perguntas elaboradas e respondidas pelos entrevistados.

\section{ANÁLISE E DISCUSSÃO DOS RESULTADOS}

Com relação à pergunta sobre a importância da utilização das Tecnologias Digitais no ensino aprendizagem, apenas o professor $F$ absteve-se de responder sobre este assunto, e o professor D que diz: "estamos aquém à tecnologia em nossos métodos educacionais hoje"; os demais Professores consideram muito importantes a utilização de tais tecnologias no ensino aprendizagem, onde as tem como ferramentas auxiliares no seu fazer pedagógico.

O professor A escreve que:

[...] o uso das tecnologias digitais no ensino muito interessante e importante, pois nossos alunos nasceram em uma era digital, e, se formos deixar isso de fora da escola com certeza perderemos o interesse do nosso público. Apesar de ter consciência que a TV, o computador e o celular são uma mania entre os alunos e que isso muitas vezes é prejudicial ao seu desenvolvimento, e que isso se deve ao mau uso que é feito deles, nós como educadores devemos aproveitar estas tecnologias e delas tirar proveito, pois se estão aí, que sejam aproveitadas para o bem.

O Professor deve estar preparado para a vinculação de processos que abordem tais tecnologias como recursos para facilitar a aprendizagem e também oportunizar o aluno a usufruir de todas as tecnologias disponíveis no ambiente Escolar.

Diante da presença destas tecnologias no dia-a-dia das pessoas, os professores B e C relatam o quanto é fundamental o uso das tecnologias digitais na nossa atuação profissional, diz que os professores devem utilizar os laboratórios de suas Escolas. O professor B coloca que aluno e professor têm assumido papéis diferentes daqueles antes típicos, essas ferramentas têm contribuído muito para o avanço ensino-aprendizagem e traz melhorias para situações de aprendizagem.

O professor $E$ demonstra grande preocupação em relação à capacitação e formação do corpo docente, diz que faltam oportunidades e melhoria de condições de trabalho:

Temos que ter professores capacitados e comprometidos com o fazer pedagógico, faz-se necessário melhorar as condições de trabalho dando-lhes melhores oportunidades, e consequentemente, permitindo que estes consigam desenvolver um ensino de qualidade mediatizando os saberes de maneira diversificada e coerente com o fazer pedagógico da 
atual sociedade, que cobra do educador um conhecimento técnico-educacional, haja vista que a escola também requer conhecimentos tecnológicos e os alunos cobram isto do profissional da educação.

Diante das colocações por professores de diferentes Escolas, na maioria percebe-se que há um comprometimento quanto à utilização das tecnologias digitais no processo ensinoaprendizagem. Pode-se dizer: novas ferramentas para velhas ideias, onde o aparecimento das tecnologias pode ser a alavanca de grandes inovações pedagógicas a serviço da construção de conhecimento, construção essa que pode ser individual, coletiva e interativa no momento em que se disponibiliza através de recursos tecnológicos o que se deseja que o aluno saiba.

Fernando Reimers (NOVA ESCOLA, 2011 p. 32), professor da universidade de Harvard, defende que a globalização e as tecnologias exigem que as escolas desenvolvam novas competências para garantir um futuro melhor aos alunos e ao país. "As escolas perdem tempo ensinando habilidades que foram úteis no passado".

Em algumas vezes, as tecnologias digitais entram com novos dispositivos técnicos e as práticas pedagógicas continuam com os velhos paradigmas, com a diferença que o professor transfere a centralidade para as tecnologias.

O papel do professor no processo educativo é fazer com que o aluno aproprie-se do conhecimento, partindo de uma reflexão crítica que aborde as tecnologias como recursos que facilitam a aprendizagem, oportunizando ao aluno a familiarização com aquelas que lhe são impostas no seu dia-a-dia; a era tecnológica, a era da informação, que flui em velocidades e em quantidades, mudando gradativamente os hábitos das pessoas, as quais se não acompanharem os avanços tecnológicos, terminam excluídos da sociedade tecnológica. Alunos e professores estão frente a um novo modo de ensinar e aprender, rompendo barreiras com a criação de novos espaços de aprendizagem. Frente ao ensino novos dilemas surgem e é objeto diário da reflexão dos envolvidos no processo educativo.

O termo tecnologia pode incluir desde as ferramentas mais simples, e os processos mais complexos já criados pelo ser humano. Pode-se dizer que a tecnologia é tão antiga quanto a História da humanidade, quando algumas pessoas começaram a inventar algumas ferramentas para suprir suas necessidades, facilitando assim sua própria sobrevivência, como a caça, a pesca e a proteção, na busca de maior habilidade do seu trabalho tornando-o mais rentável com criações simples ou mais complexa, com isto estão usufruindo das tecnologias.

A tecnologia surge das necessidades do ser humano. É assim que se apresenta, nascendo na maioria das vezes de uma necessidade simples e se tornando peça fundamental para vida de toda uma sociedade, quando as informações são transformadas em conhecimento. Processo este executado na relação entre educação, técnicas metodológicas, escola, ser humano e saber. A história da tecnologia acompanha a cronologia do uso dos recursos naturais, desde as ferramentas e fontes de energia mais complexas.

Com relação à pergunta sobre as ferramentas digitais utilizadas no processo ensino aprendizagem e o emprego das mesmas no cotidiano do professor, percebe-se que os recursos didáticos mais utilizados ainda são o retroprojetor, o DVD e a máquina de xérox, pois, para muitos, o computador é "complicado" (este merece destaque dentre as tecnologias). O computador fará parte da nossa vida, como já ocorre, ele será simples e descomplicado, de modo que o usaremos sem saber que estaremos usando. O computador tem na Escola uma utilidade muito maior que os demais recursos e deve ser mais bem explorado na sala de aula. 
Quanto ao emprego das Tecnologias Digitais como processo de ensino-aprendizagem e a utilização das mesmas, os professores A e B acreditam que o uso das tecnologias digitais no ensino é muito interessante e importante, diz que usa o computador, data show, televisão, DVD, CD e máquina fotográfica Digital para registrar as atividades feitas pelos alunos. O professor B desenvolve atividades de pesquisa no laboratório de informática com o acesso a internet e também utiliza a sala digital de sua Escola (lousa digital) na busca de novos modelos pedagógicos de apoio ao ensino, oferecendo possibilidades de desenvolver hipóteses, teses, análises, conceitos, e outros. O outro professor (C) também faz uso da internet com jogos que envolvem operações e ortografia, verificando o que é preciso retomar, diz que é uma forma de avaliar seu próprio trabalho e a aprendizagem de cada um dos alunos sem mencionar que está avaliando os conhecimentos adquiridos por estes.

Os professores E e $\mathrm{F}$ não se utilizam de ferramentas tecnológicas em sua práxis pedagógica, sendo que o professor E diz não possuir laboratório na Escola onde trabalha, mas,

"procuro no planejamento do meu trabalho estar buscando, através de pesquisa tecnológica, atividades novas para o desenvolvimento e interesse dos meus alunos", enquanto o professor F diz que: "... sou uma profissional extremamente "arcaica", e ainda não senti necessidade de usá-las e nem por isso meu trabalho foi contestado".

Analisando as respostas acima colocadas por professores em atuação, preocupam determinadas respostas fornecidas, pois, na era digital ainda se encontram Escolas que não possuem determinada tecnologia. A tecnologia auxilia o aprendizado e o seu desconhecimento poderá gerar no mundo atual o mesmo tipo de exclusão que sofre o analfabeto no mundo da escrita. A utilização de novas formas de interação atende às necessidades dos alunos, levando-os a ter maior interesse pelo aprendizado.

Segundo Arruda (2004, p. 14),

a utilização de tecnologias educacionais no contexto escolar está inserida em uma realidade econômica mais ampla, marcada por um processo de reestruturação capitalista" que gerou a organização de movimentos de mudanças pedagógicas, não apenas no Brasil, como também em outros países, como, Chile, Portugal e Espanha.

Através das tecnologias, é evidente o acesso rápido e eficiente à aquisição de informações para a construção da aprendizagem; é relevante e diversificada a melhoria da qualidade da comunicação entre professores e alunos viabilizada pelas ferramentas interativas. Percebe-se também o docente que vê na tecnologia uma forma de melhor qualificar sua práxis pedagógica. Por esse motivo, o professor deve cada vez mais participar de formação continuada e aprimorar o seu aperfeiçoamento.

As tecnologias transformam as práticas de produção, geram um maior consumo de determinados produtos quando expostos na mídia e via internet, gera competição entre os agentes de produção e alteram a própria cadeia de geração de valor.

É prioritário reconhecer que os recursos tecnológicos digitais estão para redimensionar as condições de acesso ao conhecimento, ampliando assim situações de aprendizagem, multiplicando o acesso à educação escolar. Faz-se necessário uma nova postura, a quebra de 
paradigmas de todos aqueles que são responsáveis pelo fazer da educação, educação de qualidade que transforme as informações em conhecimentos.

De acordo com a entrevista, no que se refere às tecnologias digitais no cotidiano do professor como processo de ensino aprendizagem, apenas um professor relata que não a utiliza, como forma de recurso na sua práxis pedagógica.

O professor A responde a pergunta que confere com o que está no subtítulo deste artigo e escreve:

"Na minha prática docente eu uso ferramentas digitais para introduzir um conteúdo através de alguma atividade no computador ou como culminância de algum trabalho com vídeo e, filmes. Aproveito jogos interativos para fixar conteúdos".

Faz-se necessário que a escola adote uma nova postura para transformar tanta informação em conhecimento e esse é o papel da Escola, quebrar paradigmas de todos aqueles que diretamente são responsáveis pelo acontecer da educação.

O professor B quando responde ao questionário escreve que: "este recurso tem por objetivo facilitar a ação docente mediada pelas tecnologias de informação e comunicação $e$ facilitar maiores recursos no processo ensino aprendizagem".

Outro professor escreve que as tecnologias produzem um diagnóstico dos alunos, melhorando o seu desempenho através de jogos, e que estes trazem prazer e satisfação às crianças.

O professor E escreve que

"Há a necessidade de o educador estar comprometido com este novo formato de sociedade e educação, com o avanço e a disseminação das tecnologias de informação e comunicação vem criando novas formas de convivência, novos textos, novas leituras, novas escritas e, sobre tudo, novas maneiras de interagir no espaço literário".

É importante destacar que um dos grandes desafios da sociedade atual é ter um sistema educacional que promova e viabilize a formação de indivíduos preparados para essa realidade, com níveis de aprendizado compatíveis com a atual necessidade social existente.

Campelo (2010, p. 17) afirma que para inserir as TICS (tecnologia de informação e comunicação) na educação, é preciso que a escola reveja sua postura educacional e não simplesmente faça uso sem ética e responsabilidade, é preciso ter o mínimo de conhecimento e uma metodologia adequada que valorizem os aspectos pedagógicos e educacionais, devendo estar estes fundamentados em uma teoria, Incorporando novos referenciais teóricos, trazendo contribuições ao processo ensino-aprendizagem e assim levando à construção do conhecimento através da interatividade.

Percebe-se que o grande desafio do educador é transformar informação em conhecimento, pelo fato de conhecimento ser a síntese, o qual deve ser vivenciado pelo educando.

Os procedimentos da práxis didática do professor devem privilegiar a construção coletiva dos conhecimentos, mediados pelos recursos tecnológicos.

Ao serem questionados sobre como o professor encara as atuais tecnologias no processo ensino-aprendizagem? As professoras A, B e C acreditam que as novas tecnologias são ferramentas que devem ser usadas a serviço da aprendizagem, procuram estar sempre atualizadas, dizem que é uma área que avança muito e o que hoje é novidade amanhã já estará ultrapassado, necessitando o professor estar sempre em constante aperfeiçoamento. 
O professor $\mathrm{D}$ acredita que a prática educativa tradicional está mais favorável no meio em que ele está inserido, apesar de já ter feito vários cursos preparatórios ainda acredita que a prática educativa tradicional esta mais favorável ao meio em que está inserido.

O professor E escreve que:

"Considero que o ensino com as atuais tecnologias no processo ensino aprendizagem deveria; questionar as relações convencionais entre professor $e$ aluno. Para tanto, define o perfil desse novo professor, ser aberto, humano, que valoriza a busca, o estimulo, o apoio e ser capaz de estabelecer formas democráticas de pesquisa e comunicação. Dentro do possível, estou me adaptando neste novo contexto, mas não é fácil. É preciso melhorar muito as condições de nossa escola, para ter um trabal ho como queremos".

O professor $\mathrm{F}$ diz que já fez vários cursos com vários módulos, inclusive com tecnologia assistiva, mas ainda prefere o material de baixa tecnologia que vai ao encontro das necessidades educacionais de seus alunos.

Ao analisar os questionamentos, através dos estudos e da pesquisa de campo acima citados, pretende-se levar à observação e reflexão sobre a real utilização das tecnologias como instrumento de mediação no processo de ensino/aprendizagem, bem como na formação dos professores. Na busca de compreender a influência destas novas tecnologias na prática pedagógica e no desenvolvimento do aluno durante todo o processo de ensino/aprendizagem, observa-se, também, a postura dos professores mediante as novas tecnologias adotadas nas escolas e a relação que eles estabelecem com as mesmas.

Para tanto, é necessário que o professor, além de conhecer essa tecnologia, saiba como a utilizar, compreendendo a necessidade do seu uso como os levando a uma abordagem interdisciplinar. Não esquecendo que o uso destes instrumentos deve ocorrer de forma planejada e consciente, com a utilização de metodologias adequadas focando sempre os objetivos que se deseja atingir.

Em um ambiente virtual de tecnologia, o estudante tem acesso a conteúdos teóricos, onde os professores, orientadores pedagógicos, facilitam e dão suporte na realização de tarefas propostas. O foco está na interação e cooperação entre os participantes que enriquece os conhecimentos individuais. A interatividade estimula o estudante a fazer leituras, pesquisar, colocar suas ideias e trocar experiências. Permite ao aluno fazer auto-avaliação e reflexão do seu desempenho garantindo desta forma a qualidade da sua aprendizagem.

A navegabilidade é prazerosa permite o usuário relacionar-se com colegas e professores, ampliar seus conhecimentos e ter uma comunicação imediata por meio de recursos digitais.

Neste contexto de interatividade, o ambiente de aprendizagem é de fácil acesso e navegabilidade onde o aluno tem acesso a conteúdos informações que se transformam em conteúdo sob a orientação do professor.

O aluno transforma as informações em conhecimento. Nestas situações de aprendizagem, o aluno pode vivenciar um processo de ação reflexiva, de articulação com a prática, de depuração e de (re) construção do conhecimento.

$\mathrm{O}$ aluno tem como aliado o professor que é o facilitador da sua aprendizagem. O professor que é o mediador e está sempre atento na aprendizagem do aluno, propiciando um ambiente favorável aos debates. 
No entanto, isto requer por parte do professor flexibilidade e responsabilidade para contemplar as questões emergentes e inusitadas, de modo que possam ser integradas aos participantes.

O mais importante é a credibilidade do professor, sua capacidade de estabelecer laços de empatia, de afeto, de colaboração, de incentivo, de manter o equilíbrio entre flexibilidade e organização (MORAN, 2000, p. 55).

Após os relatos, conclui-se que o Professor tem de estar aprendendo e reaprendendo com as novas tecnologias. Este deve estar aberto e disposto a buscar e receber novos conhecimentos e desafios através de pesquisas e aprimoramentos para que realmente transmitam aos alunos o conteúdo de maneira que estes apreendam.

A base da aprendizagem está na informação de forma organizada e significativa, a informação transformada em conhecimento, as tecnologias ajudam a encontrar o que está consolidado e a organizar o que está confuso, daí a importância de dominar ferramentas em busca da informação e saber interpretar o que se escolhe, adaptá-lo ao contexto pessoal e regional e situar cada informação dentro do universo de referências pessoais.

O foco da aprendizagem é a busca da informação significativa, da pesquisa, o desenvolvimento de projetos e não predominantemente a transmissão de conteúdos específicos. As aulas se estruturam em projetos e em conteúdos. A Internet está se tornando uma mídia fundamental para a pesquisa. $O$ acesso instantâneo a portais de busca, a disponibilização de artigos ordenados por palavras-chave facilitaram em muito o acesso às informações necessárias. Nunca como até agora professores, alunos e todos os cidadãos possuíram a riqueza, variedade e acessibilidade de milhões de páginas WEB de qualquer lugar, a qualquer momento e, em geral, de forma gratuita (MORAN, 2000, p. 12).

O educador sempre foi importante e continua sendo, não como repetidor de informações prontas, mas como mediador. O professor é um pesquisador e ao mesmo tempo um articulador de aprendizagens, avaliador dos resultados onde o seu papel é criativo ao invés de repetitivo.

A Educação hoje passa por um processo de transformação na área da comunicação entre aluno e professor, é mais interessante ser um educador dentro de um contexto comunicacional, interativo e participativo, já não se pode mais ensinar com autoritarismo, com o uso das tecnologias pode-se vivenciar processos participativos de compartilhamento entre o ensinar e o aprender, através de uma comunicação aberta, de constante motivação num processo dinâmico e amplo.

Só podemos educar para a autonomia, para a liberdade com autonomia e liberdade. Uma das tarefas mais urgentes é educar o educador/pai para uma nova relação no processo de ensinar e aprender, mais aberta, participativa, respeitosa do ritmo da cada aluno, das habilidades específicas de cada um (MORAN, 2000, p. 15).

Segundo Moran, percebe-se o quanto é importante ser e ter educadores maduros emocionalmente e comunicacionalmente facilitando assim todo o processo de organizar a aprendizagem. Professores sensíveis e humanos que valorizem mais a busca que o resultado pronto, estimulando e apoiando a crítica estabelecendo formas democráticas de pesquisa e de comunicação. 


\section{CONSIDERAÇÕES FINAIS}

Este trabalho obteve, entre outros objetivos, o de analisar os desafios dos docentes e, evidenciar as novas tecnologias como mais um recurso para o processo de ensino aprendizagem.

Ressalta-se a importância de esclarecer sobre tecnologia, pois ainda se pensa que tecnologia é apenas o computador, poucos encaram outros meios, mas aqui o que importa não é ter uma nova tecnologia, mas, sim, saber utilizá-la com objetivos definidos. Sabemos que é preocupante a falta de disponibilidade de recurso tecnológico em algumas escolas, na maioria das vezes se tem o quadro que é o recurso mais tradicional, mas a sugestão é que cada vez mais as tecnologias sejam como fomentadoras do trabalho professor/aluno e não como um empecilho desse trabalho.

Ensinar exige segurança e competência profissional... Quanto mais penso sobre à prática educativa, reconhecendo a responsabilidade que ela exige de nós, mais me convenço do nosso dever de lutar para que ela seja realmente respeitada (FREIRE, 2001, p. 102).

De acordo com Freire, observa-se que ao inserir as Tecnologias Digitais na Educação, é preciso que a escola reveja sua postura educacional e não simplesmente faça uso sem ética e responsabilidade, se faz necessário que o corpo docente tenha o mínimo de conhecimento e uma metodologia adequada na valoração dos aspectos pedagógicos e educacionais, devendo estar esta de acordo com a práxis do conhecimento, preocupada com o processo de ensino aprendizagem interativa, visando Educação de Qualidade, aqui entendida como a que se faz através da formação continuada de professores.

Reitera-se que esta pesquisa pautou-se numa fundamentação ampla da educação como um direito cuja finalidade maior é o desenvolvimento humana sendo a prática pedagógica intencional transformadora. E que é preciso levar em conta o grau de responsabilidade social e política onde há uma sociedade diante de tantas diferenças sociais, como as observadas no Brasil.

Este trabalho teve como objetivo analisar a importância das Tecnologias Digitais no processo de ensino/aprendizagem. Constatou-se que as Tecnologias o que constitui um importante meio para o desenvolvimento das atividades e assim da aprendizagem já estão presentes na maioria das instituições de ensino e os decentes devem ter habilidades tecnológicas para desenvolver sua práxis Educativa voltada a Inclusão Digital.

O que esta pesquisa deixa como reflexão é que as instituições devem oferecer aos docentes formações em tecnologia, para que os mesmos sintam-se seguros e capazes de atender aos discentes, estes, pode-se dizer "natos" da Era Tecnológica.

Para que os alunos participem de todo o processo educativo, devemos ter como parte central de nossa prática pedagógica uma didática que reconheça o aluno como receptor e construtor do conhecimento, onde ele se sinta responsável e comprometido pela sua aprendizagem, tornando assim, o processo mais dinâmico e interessante, onde ele possa interagir com o educador e com as tecnologias disponíveis no processo ensino/aprendizagem.

Para tal, a utilização das mídias e da tecnologia se faz presente, de forma a auxiliar o professor durante todo o processo, tornando o ensino mais contextualizado e significativo.

Apesar de que muitos caminhos possam ser sugeridos para orientar currículos e propor o uso das Tecnologias na educação, se faz reconhecer a importância de contextualizar esse uso na concretude da ação educativa, abrindo-se, por essa via, a possibilidade de tecer vivências, 
aprendizagens e saberes que surjam como significativos para cada professor em sua práxis educativa, ou seja, em cada local e em cada tempo educativo.

Entende-se, pois, que o educador da era digital deve ser capacitado para tornar seus alunos capazes de navegar no mar de informações que a tecnologia disponibiliza atuando como um estimulador do processo de seleção crítica e organização das informações. Os jovens ainda que muito hábeis no manuseio das Tecnologias, não possuem a maturidade suficiente, para a seleção e organização da informação coletada. É nesse momento que o professor deve intervir, pois é papel do professor despertar a curiosidade, a criticidade auxiliando nas sínteses e reflexões, estimulando o aluno a construir o conhecimento, pois a qualidade mais valiosa é a capacidade de transformar dados em conhecimento.

\section{AGRADECIMENTOS}

A todos que contribuíram e navegaram neste mar de aprendizagem: colegas de curso, professores, mas principalmente aos orientadores que me direcionaram no rumo certo neste mar de conhecimento.

"Meu mestre deu a partida É hora, vamos embora Vamos embora..." (Corrida de Jangada - Edu Lobo e Capinam).

\section{REFERÊNCIAS BIBLIOGRÁFICAS}

EDUCAÇÃO INFANTIL, INFÂNCIA E CIBERCULTURA, Como educar a geração que já nasceu no mundo digital. Jul/set/2011. Pátio. ARTMED, ano IX, n. 28. Entrevista concedida por Ramon M. Consenza.

FREIRE, Paulo. Pedagogia da Autonomia. Saberes Necessários à prática educativa. São Paulo: Paz e Terra, 1996 (coleção leitura).

LAKATOS, Eva Maria; MARCONI, Marina Andrade. Metodologia do trabalho científico: procedimentos básicos, pesquisa bibliográfica, projeto e relatório, publicações e trabalhos científicos. 7.ed. São Paulo: Atlas, 2007.

MORAN, Manuel José. As muitas formas de comunicarmo-nos. Trecho do segundo capítulo do meu livro Desafios na comunicação pessoal,3. ed, Paulinas, 2007, p.43-50. Disponível [Online] em 15 de maio de 2011.

Como utilizar as tecnologias na escola. Disponível [Online] em

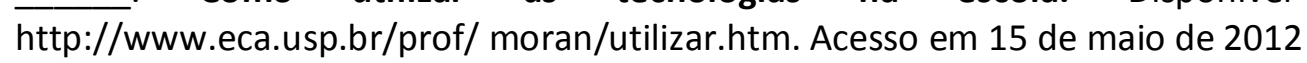

. Disponível em http://www.edapeci-ufs.net/ANAIS/04/ 025JOSEALDON2.pdf . Acesso: 21/01/2012.

MORAN, José Manuel; MASETTO, Marcos; BEHRENS, Marilda. Novas Tecnologias e Mediação Pedagógica. 16. ed. Campinas: Papirus, 2009, p.12-17

PARÂMETROS CURRICULARES NACIONAIS. Terceiro e quarto ciclos do ensino fundamental: introdução aos parâmetros curriculares nacionais. Secretaria de Educação Fundamental. Brasília: MEC/SEF, 1998. 174p.

PERRRENOUD, Philippe. A Prática Reflexiva no Oficio do Professor Profissionalização e Razão Pedagógica. Porto Alegre/RS: ARTMED, 2002, p.231. 
PRETTO, Nelson. PINTO, Cláudio da Costa. Tecnologias e Novas Educações. Revista Brasileira de Educação, v.11, n. 31, jan/abr.2006

REVISTA ESCOLA. Disponível em http://revistaescola.abril.com.br/politicas-publicas entrevistafernando-reimers-636888.shtml . Acesso em 27/11/2011

REVISTA NOVA ESCOLA. Abril, ano XXVI, n. 240, março de 2011. . Abril, ano XXV, n. 243, junho/julho de 2011. . Abril, ano XXVI, n. 247, novembro de 2011.

SANTAROSA, Lucila Maria Costi (org.). Tecnologias Digitais Assistíveis. Porto Alegre/RS: JSM Comunicação, 2010, 360p.

TARDIF, Maurice. Saberes Docentes e Formação Profissional. 9. ed. Petrópolis/RJ: Vozes. 2008, $325 p$. 